\title{
A Failure Criterion for Rocks Based on True Triaxial Testing
}

\author{
Chandong Chang $\cdot$ Bezalel Haimson
}

Published online: 18 July 2012

(C) Springer-Verlag 2012

\section{List of Symbols}

$\sigma_{1}, \sigma_{2}$ and $\sigma_{3}$ Major, intermediate, and minor effective principal stresses, respectively

$\tau_{\text {oct }} \quad$ Octahedral shear stress

$\sigma_{\text {oct }} \quad$ Octahedral effective normal stress

$\sigma_{\mathrm{m}, 2} \quad$ Mean effective normal stress acting on the failure plane

$c \quad$ Cohesion

$\phi \quad$ Angle of internal friction

$A, n, a, b \quad$ Material constants

\section{Description}

The failure criterion based on true triaxial testing considers the effect of all three principal stresses on rock compressive strength, and is entirely based on true triaxial tests conducted on rectangular prismatic specimens subjected to three independent principal stresses. The failure criterion is commonly expressed in terms of the octahedral shear stress as a monotonically increasing function of the mean effective normal stress acting on the plane of failure. In tests conducted thus far the function best fitting experimental data is the one obeying the power law. This criterion was

C. Chang ( $\square)$

Department of Geology, Chungnam National University, Daejeon 305-764, South Korea

e-mail: cchang@cnu.ac.kr

\section{B. Haimson}

Geological Engineering Program, Department of Materials

Science and Engineering, University of Wisconsin,

Madison, WI 53706, USA

e-mail: bhaimson@wisc.edu first derived by Mogi (1971) and confirmed for several other rocks by Haimson and Chang (2000), Chang and Haimson (2000), Oku et al. (2007) and Lee and Haimson (2011).

\section{Background}

The significant observation by Murrell (1963) and Handin et al. (1967) that rock compressive strength in experiments conducted in conventional triaxial extension $\left(\sigma_{1}=\sigma_{2}>\sigma_{3}\right)$ is higher than in conventional triaxial compression $\left(\sigma_{1}>\sigma_{2}=\sigma_{3}\right)$, provided convincing evidence that the effect of the intermediate principal stress on rock failure cannot be ignored and should be further studied.

In a 1971 seminal paper, Mogi (1971) reported the results of tests conducted in a true triaxial testing apparatus that enabled the application of three independent and unequal orthogonal compressive loads to each pair of faces of a rectangular prismatic rock sample. His experiments demonstrated the systematic variation of rock strength as a function of $\sigma_{2}$ for constant $\sigma_{3}$. He produced the first comprehensive set of rock true triaxial strength data for Dunham dolomite (Fig. 1a) and other rocks, which unequivocally demonstrated the strong dependence of rock strength on $\sigma_{2}$ for given $\sigma_{3}$ magnitudes. Mogi attempted to find a simple relationship that would satisfy all his true triaxial experimental results. Nadai (1950) had propounded as early as 1950 a 3D failure criterion for brittle materials by which failure occurs when the octahedral shear stress $\left(\tau_{\text {oct }}=\frac{1}{3} \sqrt{\left(\sigma_{1}-\sigma_{2}\right)^{2}+\left(\sigma_{2}-\sigma_{3}\right)^{2}+\left(\sigma_{3}-\sigma_{1}\right)^{2}}\right)$ has reached a critical value in terms of the octahedral effective normal stress $\left[\sigma_{\text {oct }}=\left(\sigma_{1}+\sigma_{2}+\sigma_{3}\right) / 3\right]$. Mogi, however, 
Fig. 1 True triaxial strength for various rock types: a Dunham dolomite (Mogi 1971), c KTB amphibolite (Chang and Haimson 2000), and e TCDP siltstone (Oku et al. 2007), and the experiment-based true triaxial failure criteria for the respective rocks $(\mathbf{b}, \mathbf{d}, \mathbf{f})$
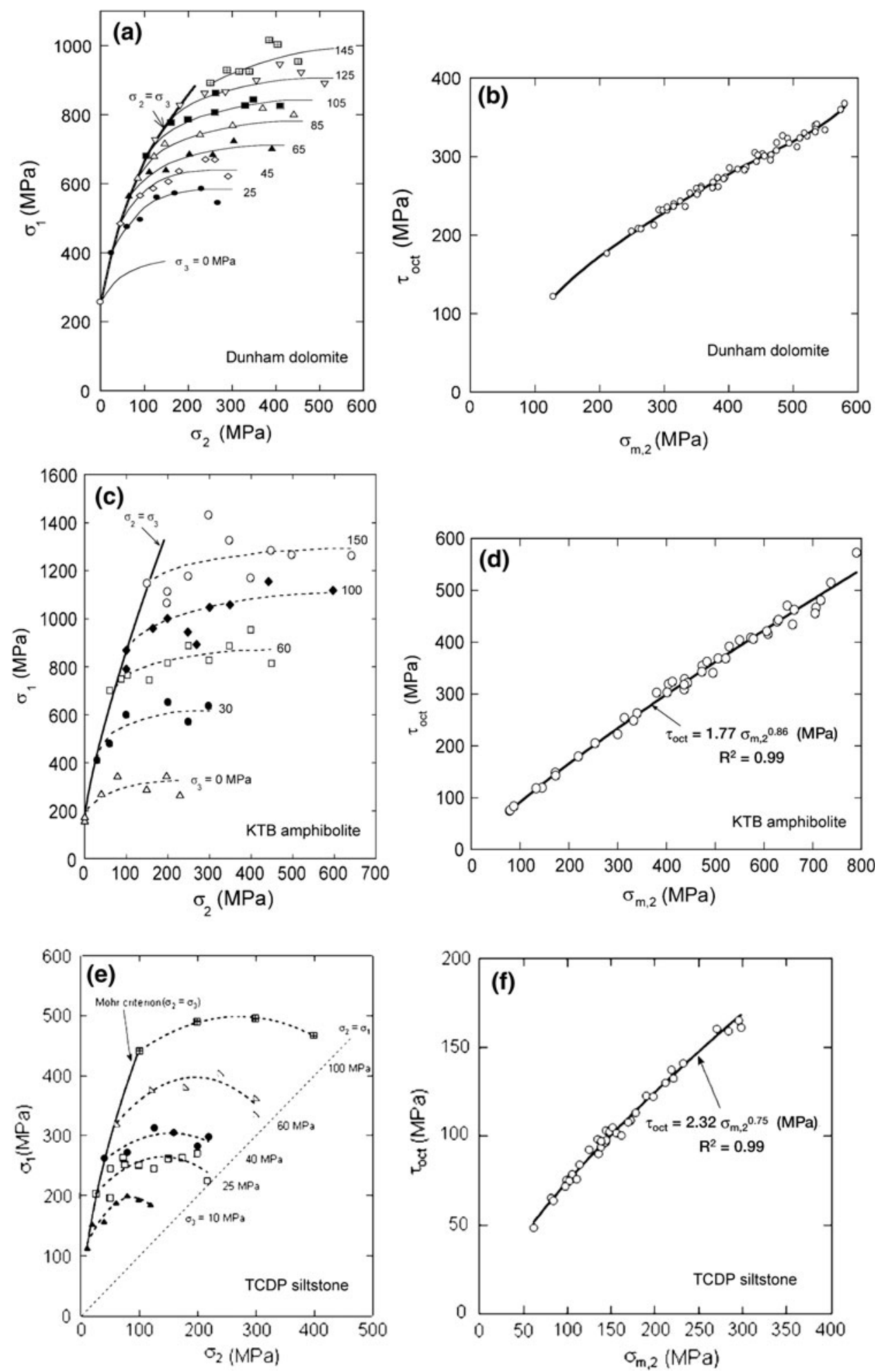

observed in his experiments that brittle failure in rocks occurs along a 2D inclined plane striking in the $\sigma_{2}$ direction, rather than in the entire specimen volume as implied by $\sigma_{\text {oct }}$. Thus, he adjusted the Nadai criterion (1950) by replacing $\sigma_{\text {oct }}$ with $\sigma_{\mathrm{m}, 2}=\left(\sigma_{1}+\sigma_{3}\right) / 2$.
Some 25 years later, Haimson and Chang (2000) tested the strength and deformability of Westerly granite in a newly designed true triaxial cell, which was similar in principle to Mogi's, but considerably more portable and servo-controlled. They derived an experiment-based true 
triaxial failure criterion for the granite which was smilar to Mogi's. Following this initial series of tests, true triaxial failure criteria were obtained for rocks extracted from three scientific deep drilling projects, KTB (the ultra deep scientific hole, Bavaria, Germany) (Chang and Haimson 2000), Taiwan Chelungpu-fault Drilling Project (TCDP) (Oku et al. 2007), and San Andreas Fault Observatory at Depth (SAFOD), USA (Lee and Haimson 2011) (Fig. 1c-f). In all these experiments, rock strength data as a function of $\sigma_{2}$ for a constant $\sigma_{3}$ follow a similar pattern to that in the Mogi's tests, and are fitted along single curves in the $\tau_{\mathrm{oct}}-\sigma_{\mathrm{m}, 2}$ domain.

\section{Formulation}

The best fitting curves for all true triaxial failure criteria, $\tau_{\text {oct }}$, obtained to date are power functions of the mean stress acting on the plane of failure, $\sigma_{\mathrm{m}, 2}$ (Mogi 1972; Haimson and Chang 2000; Chang and Haimson 2000; Oku et al. 2007; Lee and Haimson 2011):

$\tau_{\mathrm{oct}}=A \sigma_{\mathrm{m}, 2}^{n}$

where $A$ and $n$ are material constants. Since Eq. (1) is purely empirical, there is no obvious direct correlation between the two constants and known rock mechanical properties. Based on existing true triaxial test results on various rock types (dolomite, limestone, trachyte, sandstone, siltstone, amphibolite, marble, shale, and granite), however, $n$ is generally $<1$ and $A$ is $>1.5$ (Al-Ajmi and Zimmerman 2005). These constraints on the two empirical constants are subject to change as more true triaxial rock strength data become available. As these empirical constants are not parameterized with any other known material properties, the true triaxial failure criterion has to be determined strictly from true triaxial experiments.

Although true triaxial strength data in various rocks are best modeled by power-law relationships between $\tau_{\text {oct }}$ and $\sigma_{\mathrm{m}, 2}$, it has been suggested that they can be approximated by linear relationships (Al-Ajmi and Zimmerman 2005):

$\tau_{\mathrm{oct}}=a+b \sigma_{\mathrm{m}, 2}$.

The merit of linearizing the criterion is that the material parameters $a$ and $b$ can be linked to known rock mechanical properties. However, this assumes that these parameters are constants of the materials. By comparing the formulations of the Coulomb failure criterion and Eq. (2), the following correlation can be made:

$a=\frac{2 \sqrt{2}}{3} c \cos \phi$

$b=\frac{2 \sqrt{2}}{3} \sin \phi$ where $c$ is cohesion and $\phi$ is the angle of internal friction, or alternatively,

$a=\frac{2 \sqrt{2}}{3} \frac{C_{\mathrm{o}}}{q+1}$

$b=\frac{2 \sqrt{2}}{3} \frac{q-1}{q+1}$

where $C_{o}$ is uniaxial compressive strength and $q=$ $(1+\sin \phi) /(1-\sin \phi)$. Thus, the linearlized true triaxial failure criterion allows the construction of a three-dimensional criterion that incorporates the three principal stresses through relatively simple rock mechanics experiments such as conventional triaxial compression tests.

There is, however, one major over-simplification in this approach. The dip angle of the shear fracture that develops upon failure is not constant, but varies with $\sigma_{2}$ for constant $\sigma_{3}$ under true triaxial testing, increasing by up to $20^{\circ}$ in some rocks as the intermediate principal stresses are raised beyond the base value of $\sigma_{2}=\sigma_{3}$ (Mogi 1971, 1972; Chang and Haimson 2000; Oku et al. 2007). Hence $\phi$, which is directly related to the fracture dip angle is also not a constant of the material, contrary to the requirement of the Mohr-Coulomb criterion.

\section{Advantages and Limitations}

The true triaxial failure criterion is entirely based on true triaxial experiments. The criterion is obtained from strength data recorded during true triaxial tests for a wide range of $\sigma_{3}$ values and $\sigma_{2}$ varying from equal to much larger than $\sigma_{3}$. All test results plotted in the form of $\tau_{\text {oct }}$ as a function of $\sigma_{\mathrm{m}, 2}$ are best fitted by a power function that defines the true triaxial failure criterion for the rock.

A practical limitation of the criterion is that it requires the use of a true triaxial testing apparatus. At this time only a few such devices are available. As the advanatages of the experiment-based true triaxial failure criteria gain more recognition, it is foreseen that standardized equipment will soon become available.

A perceived shortcoming of Eq. (1) is that when applied to individual plots of $\sigma_{1}$ at failure as a function of $\sigma_{2}$ for constant $\sigma_{3}$ (Fig. 1a, for example), it predicts that the strength when $\sigma_{2}=\sigma_{1}$ is the same as when $\sigma_{2}=\sigma_{3}$, which is not in agreement with previous conventional triaxial test results, in which strength in triaxial extension was shown to be generally higher by some $10-20 \%$ than that in triaxial compression (Murrell 1963; Handin et al. 1967). Two counter arguments are noted: (1) the failure criterion represented by Eq. (1) is strictly empirical, i.e. a best fitting curve to experimental data in the $\left(\tau_{\mathrm{oct}}-\sigma_{\mathrm{m}, 2}\right)$ domain, and the appropriateness of its use in the $\left(\sigma_{1}-\sigma_{2}\right)$ domain is 
unclear, and (2) in most realistic field conditions, $\sigma_{2}$ is seldom larger than about 5 times the magnitude of $\sigma_{3}$, and for this condition, the criterion is clearly correct even in the $\left(\sigma_{1}-\sigma_{2}\right)$ domain.

\section{Recommendations}

When selecting an appropriate failure criterion, it is important that it represents correctly the rock strength under generalized compressive stress conditions prevailing in the earth's crust. This means that a failure criterion should be based on rock strength data obtained under controlled true triaxial stress conditions. The true triaxial failure criterion is backed up by such experimental data. Thus, the use of the experiment-based true triaxial failure criterion is recommended for a variety of conditions of compressive stresses whenever comprehensive true triaxial strength data are available.

True triaxial failure criteria are particularly needed in situations where all three principal stresses are widely differential, as is the case in the vicinity of a borehole wall. The experiment-based criterion was successfully employed in two major international research projects in conjunction with in situ stress measurements using a hybrid method involving hydraulic fracturing and borehole breakouts (Vernik and Zoback 1992). The true triaxial failure criteria and the logged breakout spans were used to derive the in situ maximum principal stress in the KTB amphibolite, Germany (Haimson and Chang 2002), and in the siltstone adjacent to Chelungpu Fault in Taiwan (Haimson et al. 2010).

\section{References}

Al-Ajmi AM, Zimmerman RW (2005) Relation between the Mogi and the Coulomb failure criteria. Int J Rock Mech Min Sci 42:431-439
Chang C, Haimson BC (2000) True triaxial strength and deformability of the German Continental deep drilling program (KTB) deep hole amphibolite. J Geophys Res 105:18999-19013

Haimson BC, Chang C (2000) A new true triaxial cell for testing mechanical properties of rock, and its use to determine rock strength and deformability of Westerly granite. Int J Rock Mech Min Sci 37:285-296

Haimson B, Chang C (2002) True triaxial strength of the KTB amphibolite under borehole wall conditions and its use to estimate the maximum horizontal in situ stress. J Geophys Res 107:2257-2271

Haimson B, Lin W, Oku H, Hung J-H, Song S-R (2010) Integrating borehole breakout dimensions, strength criteria, and leak-off test results to constrain the state of stress across the Chelungpu Fault, Taiwan. Tectonophysics 482:65-72

Handin J, Heard HC, Magouirk JN (1967) Effect of the intermediate principal stress on the failure of limestone, dolomite, and glass at different temperature and strain rate. J Geophys Res 72:611-640

Lee H, Haimson B (2011) True triaxial strength, deformability, and brittle failure of granodiorite from the San Andreas Fault Observatory at Depth. Int J Rock Mech Min Sci 48:1199-1207

Mogi K (1971) Fracture and flow of rocks under high triaxial compression. J Geophys Res 76:1255-1269

Mogi K (1972) Effect of the triaxial stress system on fracture and flow of rocks. Phys Earth Planet In 5:318-324

Murrell SAF (1963) A criterion for brittle fracture of rocks and concrete under triaxial stress, and the effect of pore pressure on the criterion. In: Fairhurst $C$ (ed) Proceedings of the 5th Symposium on Rock Mechanics. University of Minnesota, Minneapolis, pp 563-577

Nadai A (1950) Theory of flow and fracture of solids, vol 1. McGrawHill, New York

Oku H, Haimson B, Song S-R (2007) True triaxial strength and deformability of the siltstone overlying the Chelungpu fault (Chi-Chi earthquake), Taiwan. Geophys Res Lett 34:L09306

Vernik L, Zoback MD (1992) Estimation of maximum horizontal principal stress magnitude from stress-induced well bore breakouts in the Cajon Pass scientific research borehole. J Geophys Res 97:5109-5119 